\title{
A disputa de concepções de território, ciência e nação na elaboração do "Mappa Geral da República dos Estados Unidos do Brasil" de 1908
}

La disputa de concepciones de territorio, ciencia y nación en el "Mapa General de la República de los Estados Unidos de Brasil" de 1908

The dispute of territory, science and nation conceptions in the "General Map of the Republic of the United States of Brazil" of 1908

Le différend sur les conceptions du territoire, de la science et de la nation dans la "Carte Générale de la République des États-Unis du Brésil » de 1908

\section{Rildo Borges Duarte}

\section{(2) OpenEdition}

\section{Journals}

Edição electrónica

URL: https://journals.openedition.org/terrabrasilis/3586

DOI: 10.4000/terrabrasilis.3586

ISSN: 2316-7793

Editora

Rede Brasileira de História da Geografia e Geografia Histórica

Refêrencia eletrónica

Rildo Borges Duarte, «A disputa de concepções de território, ciência e nação na elaboração do "Mappa Geral da República dos Estados Unidos do Brasil" de 1908», Terra Brasilis [Online], 11 | 2019, posto online no dia 31 agosto 2019, consultado o 05 dezembro 2022. URL: http://journals.openedition.org/ terrabrasilis/3586 ; DOI: https://doi.org/10.4000/terrabrasilis.3586

Este documento foi criado de forma automática no dia 5 dezembro 2022.

All rights reserved 


\section{A disputa de concepções de território, ciência e nação na elaboração do "Mappa Geral da República dos Estados Unidos do Brasil" de 1908}

La disputa de concepciones de territorio, ciencia y nación en el "Mapa General de la República de los Estados Unidos de Brasil" de 1908

The dispute of territory, science and nation conceptions in the "General Map of the Republic of the United States of Brazil" of 1908

Le différend sur les conceptions du territoire, de la science et de la nation dans la "Carte Générale de la République des États-Unis du Brésil » de 1908

Rildo Borges Duarte

\section{Introdução}

1 Na transição do século XIX para o século XX, diversos projetos de modernização do território brasileiro se materializavam ou estavam em discussão nas altas esferas do governo federal e até em instituições como o Clube de Engenharia e a Sociedade de Geografia do Rio de Janeiro. Da expansão das redes ferroviárias e telegráficas ao melhoramento dos portos e reformas urbanas, todas essas demandas por infraestrutura eram acompanhadas por polêmicas e discursos inflamados de políticos e engenheiros, dispostos a fazer valer suas ideias - que articulavam noções de território, ciência e nação.

2 Não por acaso, essas discussões sobre o processo de modernização capitalista do território brasileiro acabavam refletidas em demandas pela produção de mapas e outras produções cartográficas. Afinal, os projetos de expansão de infraestrutura, 
principalmente para as áreas interiores do país acabavam acontecendo de maneira conjunta ao processo de reconhecimento e mapeamento. Neste sentido, também foram alvo de intensas polêmicas os processos de consecução dos trabalhos de produção cartográfica sobre o território brasileiro.

Uma destas disputas se referia ao Mapa Geral da República dos Estados Unidos do Brasil, organizado pelo Ministério da Indústria, Viação e Obras Públicas (MIVOP) e publicado durante a Exposição Nacional de 1908, em comemoração ao centenário da abertura dos portos. Entre os personagens e instituições envolvidos estavam engenheiros ligados à Repartição Geral do Telégrafos (RGT) e ao Clube de Engenharia, que naquele momento se via às voltas em discussões sobre a necessidade da elaboração, pelo governo Federal, de um mapa geral do Brasil. Entre disputas sobre métodos de construção de mapas, emergiam as concepções sobre qual tipo de ciência seria instrumentalizada pelos engenheiros deveria contribuir para a fazer o Brasil adentrar no rol das ditas "nações civilizadas e modernas".

\section{A demanda por um mapa geral do Brasil no início do século $X X$}

4 No início do século $\mathrm{XX}$, os trabalhos de reconhecimento, catalogação e posterior sistematização de materiais cartográficos sobre o território brasileiro eram fonte de preocupação e de intensas disputas e polêmicas entre aqueles que se consideravam a "elite técnica" capaz de realizar esses serviços, os engenheiros civis e militares, muitos deles ligados a instituições como o Clube de Engenharia e a Sociedade de Geografia do Rio de Janeiro.

5 Como mostra o artigo "Carta Geral do Brazil", publicado no dia 12 de junho de 1908, na segunda página do periódico carioca $O$ Paiz, onde tradicionalmente publicavam-se os artigos de opinião, as questões sobre a cartografia nacional começavam a ganhar mais força com a autorização estatal para dotação orçamentária ao projeto de levantamento da Carta Geral da República. Assim,

O n. V do artigo 22 da lei n. 1841, de 31 de dezembro de 1907, autoriza o poder executivo a "promover por meios os mais expeditos o levantamento da carta geral da Republica, abrindo para esse fim os necessarios creditos, e entrando em accordo com os governos dos Estados, que tiveram serviços dessa natureza já realizados". (Moraes Rego, 1908: 2)

O autor do artigo, o engenheiro Fábio Hostílio Moraes Rego (1849-1918), tinha um histórico de atuação profissional que explicava seu interesse nas questões de reconhecimento e mapeamento do território brasileiro. Entre as principais funções que desempenhou, na transição dos séculos XIX para o XX, destaca-se seu papel como funcionário público no Observatório Imperial Astronômico, como lente substituto da Politécnica do Rio de Janeiro e na construção da Estrada de Ferro Sobral e na Companhia de Melhoramentos Hidráulicos do Maranhão. Além disso, também participou de empreendimentos privados, na construção da Estrada de Ferro São PauloRio Grande e emitindo estudos e pareceres para o Centro Industrial do Brasil, ${ }^{1}$ instituição formada em 1904 a partir da fusão da Sociedade Auxiliadora da Indústria Nacional (SAIN) com o Centro de Fiação e Tecelagem de Algodão, sob a direção de Jorge Luís Gustavo Street (1863-1939). ${ }^{2}$ Essa longa trajetória profissional pode ser rastreada 
em algumas passagens do artigo publicado em defesa da construção da carta geral do Brasil.

7 Assim, logo após fazer o chamado ao governo federal para executar a autorização dada pela Lei Orçamentária para o ano de 1908, Hostílio passa a criticar as produções cartográficas feitas por diferentes iniciativas, particulares e governamentais. Segundo o engenheiro, os mapas produzidos ou ainda em processo de finalização até aquele período eram, do ponto de vista técnico, "inconfiáveis" e não dariam uma "ideia precisa das condições geográficas do país”. 0 único trabalho que mereceria algum crédito seria aquele realizado pela Comissão da Carta do Império (1862-1878), empreendimento do qual Fábio Hostílio chegou a participar enquanto era diretor interino do Observatório Imperial, sendo encarregado pela seção responsável por finalizar a produção da Carta Geral, contando com os trabalhos feitos na Carta provisória elaborada para a Exposição Universal da Filadélfia de 1876. Dessa maneira,

Como encarregado da produção da Carta, Moraes Rego prepara um relatório das suas atividades, registrando as críticas feitas por Manoel Pereira Reis e a necessidade de se elaborar uma nova Carta. Esta, iniciada por Pereira Reis, foi completada por Moraes Rego, que utilizou os trabalhos de Mouchez e de W. Chandless, considerados, por ele, como os mais modernos em termos de conhecimento geográfico, ou melhor, posições geográficas sobre o país. (Fadel, 2005: 23)

8 Não por acaso, Hostílio teceu elogios à capacidade técnica do almirante Mouchez nos trabalhos de mapeamento realizados na região costeira do Brasil, mesmo que muitos detalhes apresentassem imperfeições e boa parte das áreas identificadas como sendo de melhor precisão se referissem apenas aos locais com maior demanda para a navegação.

Nos parágrafos seguintes, o engenheiro buscaria referendar suas críticas ao estado da arte dos trabalhos cartográficos no Brasil a partir de menções ao relatório produzido pelo geólogo estadunidense Charles Hartt (1840-1878) ${ }^{3}$ quando este chefiava a Comissão Geológica do Império. Havia ali uma crítica ao estado da arte da cartografia no Brasil, notadamente aos trabalhos de levantamento topográfico. Segundo o cientista estadunidense, muitos mapas deste período retratavam "serras que não existem" ou "acidentes geográficos" com baixíssima precisão. Neste sentido, a produção cartográfica brasileira era de tal modo ineficiente que os trabalhos iniciais de reconhecimento do satélite natural da Terra apresentavam produções mais confiáveis, a tal ponto que Hostílio encerrava suas críticas afirmando ser "qualquer mapa da Lua mais exato que a melhor Carta do Brasil".

10 Após a saraivada de críticas às produções cartográficas sobre o território brasileiro até aquele momento, Hostílio passa, nos parágrafos seguintes, a propor processos e métodos que pudessem contribuir com a produção da carta geral do Brasil. Assim, à obsessão pela exatidão e rigor do "homem de ciência" se integra o "homem de negócios", interessado em resolver da maneira mais pragmática possível os entraves à modernização capitalista do território brasileiro. ${ }^{4}$

11 Grandes obras de infraestrutura como melhoramento de portos, ferrovias e saneamento foram alguns dos trabalhos realizados por Hostílio ao longo de sua carreira. Não por acaso, eram latentes suas preocupações com o planejamento territorial e a modernização capitalista, sendo estes possíveis apenas com a aplicação de rápidos processos de reconhecimento e mapeamento. Assim, o engenheiro sempre foi um ferrenho defensor dos "métodos expeditos". Nesse sentido, 
[...] o levantamento expedito dará uma idéa precisa de todo o território, com os seus principaes accidentes, e podendo servir de guia ao viajante ou geologo, ao immigrante e ao capitalista que desejar empregar o seu dinheiro no desenvolvimento do nosso paiz. Uma carta obtida nas condições assim delineadas, não será uma carta topographica na accepção rigorosa desta palavra, onde os menores detalhes devem ser rigorosamente determinados; será uma carta geographica, cujos resultados já serão bastantes completos para as necessidades do Brazil. (Moraes Rego, 1908: 2)

O referido artigo chegaria às reuniões ordinárias do Clube de Engenharia do Rio de Janeiro, instituição que se colocava à frente das questões sobre o processo de modernização do território brasileiro e onde, naquele momento, a demanda por produções cartográficas alcançava o topo das pautas da instituição carioca. Apenas quatro dias após a publicação do artigo de Fábio Hostílio, no dia 16 de junho de 1908, o presidente do Clube, André Gustavo Paulo de Frontin (1860-1933), atendeu o pedido de parecer sobre o artigo, insistindo ser aquela "questão da maior importância" para o país. As discussões por esse parecer se arrastariam durante os meses subsequentes em diversas reuniões ordinárias da instituição.

E foi justamente durante as discussões sobre a necessidade de realização de uma carta geral do Brasil que uma polêmica, então recente, sobre o Mappa Geral da República dos Estados Unidos do Brasil, organizado para ser apresentado durante a Exposição Nacional de 1908, foi reacendida.

\section{As polêmicas sobre o mapa da Exposição Nacional de 1908}

14 A motivação para a realização de uma Exposição Nacional em 1908 surgiu por uma demanda dos idealizadores e participantes do Congresso de Expansão Econômica, realizado em 1905, além de setores da imprensa carioca, e seria destinado a marcar o centenário da entrada do país no "mundo civilizado", simbolizado pela abertura dos portos às nações amigas em 1808. Após a aprovação orçamentária do Congresso Nacional, em 1907, a exposição foi organizada e ocorreu entre 15 de junho e 7 de setembro de 1908, tendo seus pavilhões constituídos no bairro da Praia Vermelha, no Rio de Janeiro ${ }^{5}$ (Figura 1). Como mostra Margareth Pereira:

Nos seus três meses de abertura, a exposição foi visitada por mais de um milhão de pagantes, muitos deles oriundos de diferentes pontos de um território em grande parte sequer conhecido pelos demais brasileiros. Todos os estados da Federação organizaram pavilhões ou estandes exibindo seus avanços culturais e econômicos em álbuns, fotografias ou catálogos. Além disso, o Governo Federal e a Prefeitura do Distrito Federal também se fizeram representar, construindo importantes pavilhões e mostrando o desenvolvimento de seus serviços públicos. (2010: 7) 
Figura 1: Portal de entrada da Exposição Nacional de 1908, no bairro Praia Vermelha da cidade do Rio de Janeiro

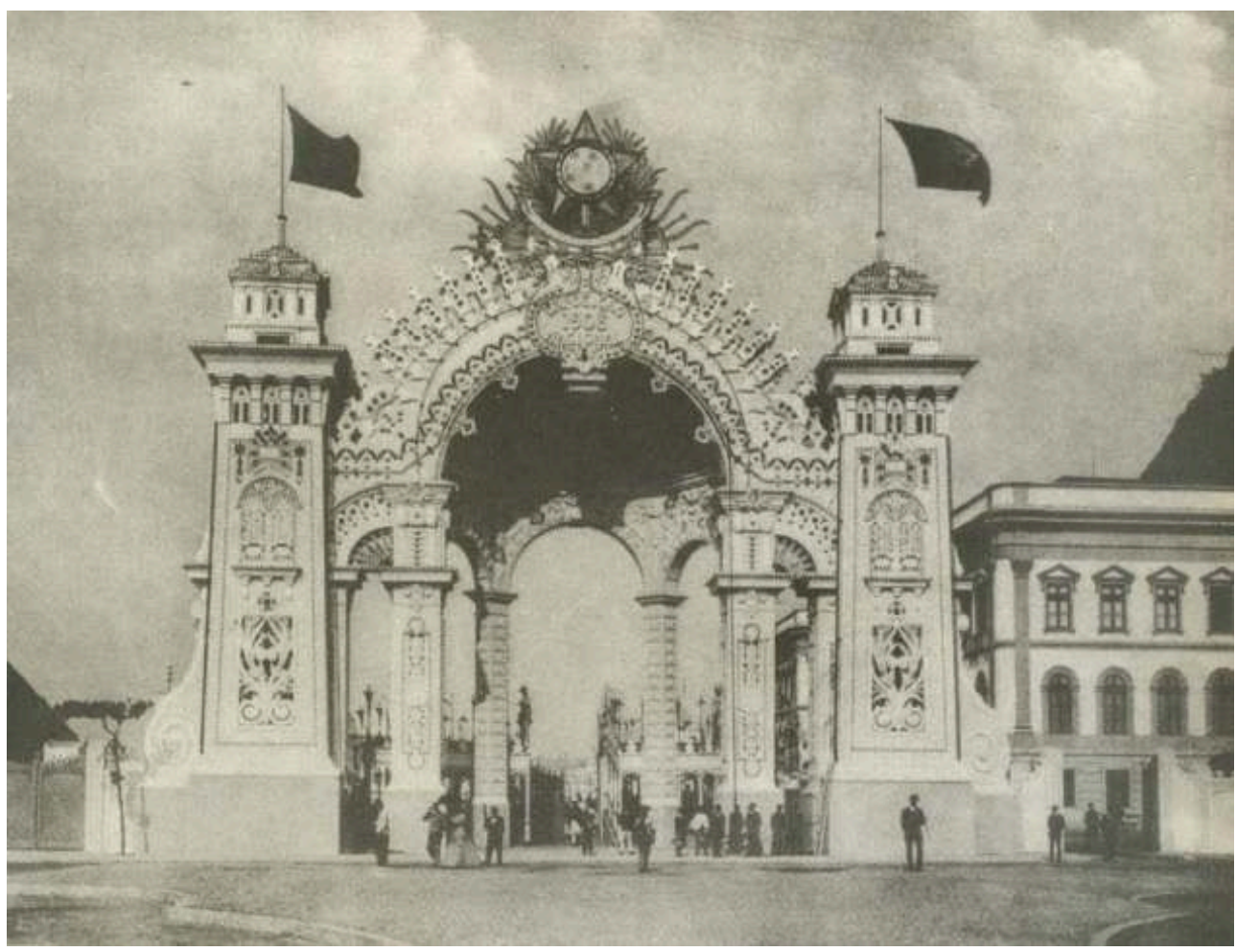

Durante três meses, a Exposição Nacional apresentou em seus pavilhões as efemérides dos estados brasileiros.

Fonte: Dunlop (1963: 71)

De certa maneira, essa exposição nacional seguia o mote das Exposições Universais onde, naquele momento da transição do século XIX para o XX, civilização e progresso técnico eram fontes de ideologia e se faziam representar nestas feiras mundiais que reuniam expositores de diversos países dispostos a apresentar as mercadorias produzidas a seus próprios territórios, visando atrair investimentos e até possíveis migrantes. ${ }^{6}$ Não por acaso, mapas eram essenciais como forma de apresentar as potencialidades das nações presentes nestas exposições. Afinal, naquele momento da geografia histórica do capitalismo, onde uma série de materialidades eram impostas e se espalhavam pela superfície terrestre, de ferrovias a linhas telegráficas, o processo de modernização só se daria a partir de um movimento, por vezes violento e até genocida, de incorporação de grandes áreas nos mais diversos territórios à lógica de produção capitalista. ${ }^{7}$ E produções cartográficas se tornavam essenciais para auxiliar neste processo.

Neste contexto, a exposição brasileira deveria contar com a produção de um mapa geral do Brasil, apresentando as efemérides territoriais, as principais vias de comunicação e demais informações importantes à apresentação do país na grande feira nacional de 1908. Foi a partir desta demanda que o MIVOP, na figura do ministro Miguel Calmon Du Pin e Almeida (1879-1935), organizou a produção deste mapa, contando com a colaboração de engenheiros da RGT. E justamente entre dois engenheiros desta instituição ocorreram as polêmicas sobre essa produção cartográfica.

O engenheiro Jerônymo Baptista Pereira, então desenhista chefe da RGT, esteve presente às reuniões do Clube de Engenharia que faziam a discussão do parecer sobre a 
necessidade de organização de um mapa geral do Brasil pelo governo federal, a partir da demanda inicial feita pelo artigo de Fábio Hostílio. Assim, em 23 de setembro de 1908, alguns dias depois do encerramento da Exposição Nacional, o engenheiro Baptista Pereira tomaria a palavra na sessão ordinária da instituição carioca e iniciaria suas críticas ao estado da arte da produção cartográfica do país. Segundo ele, desde

a morte de Beaurepaire Rohan, com o ostracismo voluntario e inexplicavel de Pereira Reis e outros geographos de valor, surgiram por toda parte verdadeiros manufactureiros, si me permittem tal expressão, de cartas geographicas, cujo unico fanal era o lucro mercantil, com menosprezo completo da dignidade e do renome da classe a que pertencemos. (Clube de Engenharia, 1913: 180)

Após essa forte afirmação sobre os "manufatureiros de mapas", Baptista Pereira iniciava seus ataques ao que considerava uma verdadeira invasão da lógica pragmática típica do mundo dos negócios e que substituía noções de básicas de ciência no que se refere à produção de mapas. Seu alvo principal era o engenheiro Francisco Bhering, ${ }^{8}$ organizador do Mapa Geral da República dos Estados Unidos do Brasil de 1908. Dessa maneira, a polêmica que em um primeiro momento tinha ficado restrita a alguns jornais cariocas 9 no início daquele ano, agora se arrastava para o Clube de Engenharia.

19 Ainda naquela reunião da instituição, Baptista Pereira diria que a "metodologia" de Bhering para a construção de cartas geográficas se daria em três passos: não necessitaria de equações; não haveria preocupação com a escolha da projeção e não precisariam apresentar grande precisão, por serem produções destinadas à propaganda (Clube de Engenharia, 1913).

20 Para finalizar, o engenheiro ainda diria que durante a elaboração do mapa a cargo da RGT, Francisco Behring teria lhe ordenado que traçasse "os grandes e accidentados rios da região amazonica por uma singela linha que percorresse o eixo dos rios e de não (se) preoccupar com a topographia, "porque esta ficaria ao gosto artistico do desenhista da Carta" (Clube de Engenharia, 1913: 190).

21 Não por acaso, após utilizar inicialmente os jornais e, mesmo depois do nome de Bhering ter sido omitido do mapa apresentado na Exposição Nacional, ainda insistir em polemizar nas reuniões do Clube de Engenharia, Baptista Pereira acabaria exonerado do seu cargo na RGT por ordens do ministro Calmon du Pin, tendo sido readmitido alguns anos depois após decisão do Supremo Tribunal Federal. ${ }^{10}$

Para além das relações políticas de Bhering, tendo entre seus principais aliados figuras como Paulo de Frontin, que auxiliariam a assumir a relatoria do Mapa do Brasil ao Milionésimo de 1922 e até a direção da RGT alguns anos mais tarde, a derrota de Baptista Pereira nesta polêmica provavelmente se deveu muito mais à visão que Bhering tinha sobre as relações entre ciência, nação e território. $O$ mapa organizado para a exposição de 1908 mostrava como o reconhecimento e o mapeamento do território brasileiro deveriam se mostrar como um saber técnico útil à gestão estatal e à facilitação dos negócios. Não por acaso, uma olhada no mapa (Figura 2) indica o destaque que foi dado às estatísticas econômicas históricas sobre os produtos que mais eram comercializados desde a abertura dos portos e a comparação do tamanho territorial do Brasil em relação às "grandes potências" da época. Também a representação da rede de comunicações, com a apresentação das linhas telegráficas e ferroviárias construídas, em construção e projetadas, indicando a necessidade de expor um país que tinha por grande projeto o processo de modernização e integração de todo território, principalmente dos chamados "sertões". ${ }^{11}$ 
Como mostra o próprio Bhering, em artigo publicado um ano antes da produção do referido mapa, fazer a propaganda e mostrar um país cada vez mais interessado na modernização capitalista importava mais do que a obsessão pela precisão topográfica. Segundo ele:

Para attrahirmos correntes de immigração, desenvolvermos emprezas fluveas, de estradas de rodagem, de ferro, culturas, etc., precizamos explorar o nosso solo em suas partes as mais recônditas, assignalando em nossas cartas os immensos chapadões, as florestas sem fim, os núcleos de população, separados frequentemente por dezenas de léguas. [...] Procedendo como estamos indicando, fechar-se-hia em breve o cyclo da geographia heroica - no Brasil e se teria incorporado á economia da República os vastíssimos sertões, os desertos chapadões, as florestas sem fim do nosso oeste, profundamente recortadas por cursos d'agua, que, melhorados, seriam estradas que transportariam as mercadorias das paragens extremas para o Atlantico. (1907: 2)

Figura 2: "Mapa Geral da República dos Estados Unidos do Brasil” - Ministério da Indústria, Viação de Obras Públicas, 1908

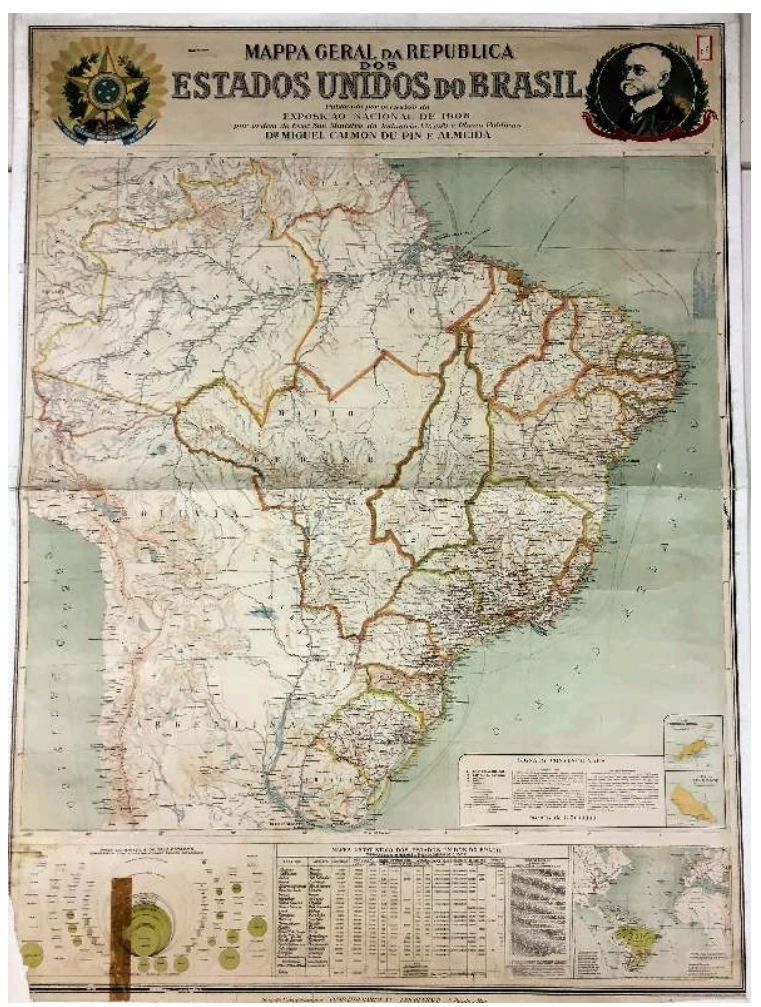

Pode-se verificar na porção superior do mapa, logo após o título, a ausência do nome de Francisco Bhering como organizador devido à polêmica com o engenheiro Baptista Pereira. Na parte inferior, constam no canto esquerdo um gráfico comparando a área territorial do Brasil com outros países e ao centro uma tabela com dados de comércio dos estados brasileiros com o mundo em 1808.

Fonte: Arquivo Nacional - Fundo Cartográfico Francisco Bhering (BR RJANRIO F4.0.MAP.74).

$\mathrm{Na}$ concepção de Bhering, o reconhecimento, mapeamento e modernização das áreas consideradas "vazias"12 só se tornariam realidade se ocorressem em conjunto com a expansão das redes de comunicação para essas regiões. Assim, mapas como o da Exposição Nacional de 1908 deveriam apresentar as possibilidades de modernização do território, daí ser mais importante retratar essas lógicas em detrimento da exatidão das representações do relevo ou das bacias hidrográficas. Antagonizar com essas perspectivas sobre território, ciência e nação que eram compartilhadas por figuras 
importantes do Clube de Engenharia e do Estado brasileiro, ${ }^{13}$ ajudam a explicar como Baptista Pereira perdeu até seu cargo público ao tentar levar até as últimas consequências suas ideias e concepções sobre a produção cartográfica do País.

\section{Considerações Finais}

De certa maneira, o mapa de 1908 indica o quanto era importante para os engenheiros manter sob sua responsabilidade as questões técnicas sobre o reconhecimento e mapeamento do território brasileiro. Não por acaso, as polêmicas sobre a produção deste mapa teriam como principal palco o Clube de Engenharia do Rio de Janeiro, que naquele momento colocava como primordial a necessidade de se produzir um mapa geral do País.

Assim, a disputa entre Pereira Baptista e Bhering, indica justamente essa demanda da engenharia nacional e a preocupação evidente em garantir ocupação aos profissionais da área, tendo como prioridade a ampliação do processo de levantamentos geográficos das áreas "vazias" do território, ou seja, aquelas áreas ainda "incógnitas", "sertões" ainda a ser incorporados à dinâmica econômica da nação. ${ }^{14}$

Fica clara a iniciativa para que as atividades geográficas de levantamento territorial, dentre as quais se incluía a cartografia, envolvendo as noções de topografia, astronomia e geodesia, deveriam ser desenvolvidas prioritariamente por engenheiros. E dentro deste campo de atuação, as concepções de território, ciência e nação acabavam muitas vezes se contrapondo e fazendo surgir polêmicas, principalmente nos processos de consecução de mapas.

Ao fim e ao cabo, vemos neste período uma cada vez maior articulação entre a atuação científica dos profissionais da engenharia com o pragmatismo dos "bons homens de negócios" que a um só tempo defendiam métodos rápidos de reconhecimento e mapeamento do território, garantindo a produção de mapas que pudessem servir aos interesses de ampliação de investimentos e de colonização em direção às áreas ainda a serem incorporadas pelas lógicas capitalistas.

\section{BIBLIOGRAFIA}

Assis, Raimundo Jucier Sousa de (2016). A iminência da subordinação aos Estados Unidos: A afirmação do Brasil como periferia do capitalismo na exposição universal de Chicago. 369f. Tese (Doutorado em Geografia Humana) - Faculdade de Filosofia, Letras e Ciências Humanas, Universidade de São Paulo, São Paulo.

Bhering, Francisco (1907). "Incognitas geographicas". In: Jornal do Commercio, Rio de Janeiro, 12 de janeiro de 1907, p.6.

Carone, Edgard (1978). O centro industrial do Rio de Janeiro e a sua importante participação na economia nacional (1827 - 1977). Rio de Janeiro: Cátedra. 
Clube de Engenharia (1913). “Atas das sessões ordinárias do conselho diretor do Clube de Engenharia - 1908”. In: Revista do Clube de Engenharia, Rio de Janeiro, n. 26, p. 2-239.

Duarte, Rildo Borges (2013). Incógnitas Geográficas: Francisco Bhering e as questões territoriais brasileiras no início do século XX. São Paulo: Alameda.

Dunlop, Charles Julius (1963). Rio Antigo. $3^{\text {a }}$ ed. Rio de Janeiro: Editora Rio Antigo.

Fadel, Simone (2005). "Engenharia e saneamento: a trajetória profissional de Fábio Hostílio de Moraes Rego (1870-1916)”. Revista da SBHC, Rio de Janeiro, v. 3, n. 1, p. 20-32.

Fadel, Simone (2006). Meio Ambiente, Saneamento e Engenharia no período do Império a Primeira República: Fábio Hostílio de Moraes Rego e a Comissão Federal de Saneamento da Baixada Fluminense. 202f. Tese (Doutorado em História Social). Universidade de São Paulo, São Paulo.

Freitas, Marcus Vinícius de (2002). Charles Frederick Hartt, um naturalista no império de Pedro II. Belo Horizonte: Editora UFMG.

Harley, John Bryan (2005). La nueva naturaleza de los mapas: Ensayos sobre la história de la cartografia. México: FCE.

Harvey, David (2013). Os limites do capital. São Paulo: Boitempo.

Maia, João Marcelo Ehlert (2008). A terra como invenção: o espaço no pensamento social brasileiro. Rio de Janeiro: Jorge Zahar Editor.

Ministério da Indústria, Viação e Obras Públicas. Mappa geral da Republica dos Estados Unidos do Brasil: publicado por occasião da Exposição Nacional de 1908 por ordem do Exmº. Sr. Ministro da Indistria, Viação e Obras Publicas Dr. Miguel Calmon Du Pin e Almeida. São Paulo e Rio de Janeiro: Lit. Hartmann-Reichenbach, 1908. 1 mapa, color., $132 \mathrm{~cm}$ x 97cm. Escala: 1:5.000.000. Arquivo Nacional, Fundo/Coleção Francisco Bhering, F4, mapa 74.

Moraes, Antônio Carlos Robert (2011). Geografia histórica do Brasil: capitalismo, território e periferia. São Paulo: Annablume.

Moraes Rego, Fábio Hostilio (1908). “Carta Geral do Brazil”. O Paiz, Rio de Janeiro, 12 de junho, p.2. Pereira, Margareth da Silva (2010). “A exposição de 1908 ou o Brasil visto por dentro”. Revista ARQTexto, Porto Alegre, n. 16, p. 6-27.

Rodrigues, Fernanda Barbosa dos Reis (2017). Os engenheiros tomam partido: Trajetórias e transformações no Clube de Engenharia (1874-1910). 185f. Dissertação (Mestrado em História Social) - Instituto de Ciências Humanas e Filosofia. Universidade Federal Fluminense, Rio de Janeiro.

Um funccionario demittido porque cumpriu seu dever (1914). Gazeta de Notícias, Rio de Janeiro, 12 de julho de 1914. p.6.

\section{NOTAS}

1. Sobre a carreira de Fábio Hostílio, ver a tese de doutorado "Meio Ambiente, Saneamento e Engenharia no período do Império a Primeira República: Fábio Hostílio de Moraes Rego e a Comissão Federal de Saneamento da Baixada Fluminense", defendida em 2006 pela historiadora Simone Fadel.

2. A SAIN foi fundada em 1827 por diferentes setores das elites econômicas do Império e contava em seus quadros com profissionais liberais. Seu principal objetivo era promover o progresso e a modernização do território brasileiro, além de ser um fórum de debates sobre os principais 
problemas do Império, principalmente em assuntos relacionados às vias de circulação, melhoramentos urbanos e àquela considerada a principal indústria brasileira à época, a agricultura. Entre 1833 e 1892, muitas destas questões eram debatidas nas páginas da revista 0 Auxiliador da Indústria Nacional, editada pela instituição. Ao dar lugar ao Centro Industrial Brasileiro, em 1904, a instituição torna-se mais pragmática e voltada especificamente aos problemas da implantação e expansão das atividades industriais no Brasil (Carone, 1978).

3. Charles Hartt fez parte da Comissão Geológica do Império (1875-1878) e publicou, em 1870, o livro Geology and physical geography of Brazil. Em uma de suas expedições pelo interior do Brasil, Hartt trouxe como integrante de sua equipe um de seus melhores alunos na Cornell University, Orville Derby, que anos mais tarde se tornaria diretor da Comissão Geográfica e Geológica de São Paulo (Freitas, 2002).

4. O tino para os bons negócios surgiu para Hostílio quando de sua participação no projeto de construção da Estrada de Ferro Sobral, em 1882, além de outros serviços ferroviários privados a partir de então. Como mostra Simone Fadel: “A construção de ferrovias se constituiu para Fábio como um vasto campo de trabalho. Ele retornou às suas atividades no campo ferroviário como primeiro engenheiro da Estrada de Ferro Central do Brasil, no ano de 1890, e voltou a atuar, já no século XX, como Diretor da Estrada São Paulo-Rio Grande. Aliás, a geração de engenheiros à qual Fábio pertenceu esteve intimamente ligada à questão de um projeto de viação para o país. Esse projeto contava basicamente com a construção de linhas ferroviárias que viabilizassem o escoamento da produção, a ligação de centros industriais incipientes, enfim, a ferrovia significava progresso material e simbólico e, portanto, consistiu em um campo privilegiado da própria constituição da engenharia nacional" (2005: 25).

5. "Coube à Praia Vermelha, a que se prendem tantas e tão belas tradições nacionais, a honra de ser escolhida para teatro deslumbrante do certame. Em breve, um formigueiro de operários, arquitetos e engenheiros (êstes últimos com o Dr. Sampaio Corrêa à frente) ali trabalhava febrilmente, dia e noite, preparando o terreno com aterros e desaterros, adaptando edifícios já existentes, construindo pavilhões e reformando o antigo cais, na base do penhasco da Urca. Poucos dias antes da inauguração, na manhã de 30 de junho de 1908, a convite do Dr. Miguel Calmon du Pin e Almeida, Ministro da Viação, o Presidente da República, Dr. Affonso Augusto Moreira Penna, acompanhado de sua espôsa e filha, a gentíl senhorita Dora, foi visitar as obras da Exposição. S. Excia. percorreu o pavilhão central, onde já se encontravam arrumados vários produtos dos diferentes Estados que não tinham construído prédio próprio, e visitou os pavilhões federais e dos Estados de Minas Gerais, São Paulo e Bahia, e também o de Portugal. Mereceu ainda sua atenção o elegante teatro, o cinematógrafo, o «rink» de patinação, os restaurantes, a ponte que dava passagem para o lago interno e as demais dependências do grande certame. Retirou-se o Chefe da Nação pouco depois das 10 horas, bem impressionado com o andamento dos trabalhos. I O velho bairro da Praia Vermelha transmudara-se por completo. Tôda a área compreendida entre o fim da rua General Severiano e o antigo edifício da Escola Militar, onde pouca coisa havia a divisar, além do vasto casarão do Hospício Nacional de Alienados (hoje Universidade do Brasil), e a deserta praia da Saudade, transformara-se, como por encanto, numa cidade, verdadeira fantasia das mil e uma noites!" (Dunlop, 1963: 72).

6. "As exposições universais eram uma prática do Ocidente e de ocidentalismo, um encontro entre materiais escritos, amostras de produtos dos cantos mais remotos do mundo e de visitantes dos diversos territórios que conformavam o globo. O caráter específico posto para as exposições universais, nos últimos cinquenta anos do século XIX, estava em se transformarem numa vitrine da geopolítica do capitalismo, constituída a partir da realização da circulação de conhecimentos detalhados sobre os Estados modernos e colonizados, da apresentação de mercadorias já inseridas nas trocas comerciais do mercado mundial, de fontes de matérias-primas ainda não exploradas e de produtos ainda em busca de investimentos. As recentes invenções de máquinas, os novos testes de produtos da natureza na produção de mercadorias, um mapeamento dos meios de 
subsistência capazes de alargar o mercado mundial, tudo isso era possível de se tornar sabido a partir das exposições universais" (Assis, 2016: 97).

7. “A geografia histórica do capitalismo tem sido absolutamente notável. Povos dotados de total diversidade de experiências históricas, vivendo em uma incrível variedade de circunstâncias físicas, têm-se unido, às vezes de modo grandioso e por convencimento, mas mais frequentemente mediante o exercício de uma força bruta implacável, em uma unidade complexa no âmbito da divisão internacional do trabalho. [...] Fábricas e campos, escolas, igrejas, centros comerciais e parques, rodovias e ferrovias se espalham por uma paisagem que tem sido indelével e irreversivelmente criada seguindo ditames do capitalismo" (Harvey, 2013: 477).

8. O engenheiro Francisco Bhering (1867-1924), nascido em Uberlândia-MG e formado na Escola Politécnica do Rio de Janeiro, membro do Apostolado Positivista, da Sociedade de Geografia do Rio de Janeiro e do Clube de Engenharia, professor das escolas politécnicas do Rio de Janeiro e de São Paulo e diretor da RGT, participou ativamente de diversos projetos ligados à modernização e integração do território brasileiro no início do século XX. Dentre eles, se destaca a elaboração do projeto de ligação de linhas telegráficas do Mato Grosso ao Amazonas que seria levado a cabo pelo então Major Cândido Mariano Rondon (Duarte, 2013).

9. Como relatado pelo próprio Baptista Pereira na reunião do Clube de Engenharia: "Por motivos amplamente divulgados pela imprensa, principalmente pela Gazeta de Notícias, fui forçado a analysar a carta que estava em construção na Repartição dos Telegraphos, sob a direção do Sr. Dr. Francisco Bhering" (Clube de Engenharia, 1913: 182).

10. Em uma nota intitulada "Um funccionario demittido porque cumpriu seu dever", datada de 12 de julho de 1914, o jornal A Gazeta de Notícias resgatava a história sobre o processo de demissão do engenheiro Baptista Pereira. Segundo o jornal, o ministro Miguel Calmon Du Pin não teria ficado satisfeito com a publicização do parecer negativo sobre o mapa geral do Brasil organizado para a exposição de 1908, atribuindo esse vazamento de informações a artigos que teriam sido publicados a mando de Bapstista Pereira, o que ocasionou sua exoneração do cargo de Desenhista da Repartição Geral dos Telégrafos. Ao fim, a publicação destacava que todos os artigos tinham sido publicados pelo próprio jornal, sem interferência do engenheiro, e que este tinha acabado de conseguir julgamento favorável no STF pela sua readmissão no serviço público.

11. Para Antônio Carlos Robert Moraes, essa valorização espacial dos sertões conformava-se em uma ideologia geográfica. Afinal, temos "um símbolo imposto - em certos contextos históricos a determinadas condições locacionais, que acaba por atuar como um qualificativo local básico no processo de sua valoração. Enfim, o sertão não é uma materialidade da superfície terrestre, mas uma realidade simbólica: uma ideologia geográfica. Trata-se de um discurso valorativo referente ao espaço, que qualifica os lugares segundo a mentalidade reinante e interesses vigentes neste processo" (2011: 101).

12. Áreas que nada tinham de "vazias", sendo este um mote ideológico concebido para facilitar o processo violento de integração territorial. Afinal, como lembra John Brian Harley, o silêncio dos mapas "se convierte en un acto ideológico afirmativo. [...] Los colonizadores potenciales ven en el mapa pocos obstáculos insuperables. Lo que menos hace en mapa es reflejar la presencia de pueblos indígenas y su huella sobre la tierra [...] Mediante estos silêncios, el mapa se vuelve un permiso para apropiarse del território descrito" (2005: 138).

13. Essa perspectiva sobre a imaginação espacial brasileira, compartilhada por Bhering e outros personagens, "está associada a questões que dizem respeito ao lugar do Brasil na civilização e à modernização liberal que varria a Europa. Não se trata apenas de revelar o sertão em busca da autenticidade, mas de pensar as possibilidades civilizatórias de uma sociedade periférica" (Maia, 2008: 53)

14. Assim, a própria atuação do Clube de Engenharia fazia parte daquele contexto onde "a criação de um campo de formação intelectual e organização profissional da engenharia civil no país desnuda as condições de fortalecimento, legitimação e consolidação de um corpo de engenheiros 
nacionais, que ocuparão espaços centrais na correlação de forças do período" (Rodrigues, 2017: $68)$.

\section{RESUMOS}

A necessidade da produção de um mapa geral do Brasil para a Exposição Nacional de 1908 gerou uma grande polêmica entre engenheiros ligados à Repartição Geral dos Telégrafos e ao Clube de Engenharia. Naquele período, a produção cartográfica sobre o território brasileiro se tornava assunto prioritário para os engenheiros e todos aqueles interessados em fazer avançar não somente o conhecimento científico sobre o território brasileiro, mas também, e principalmente, promover o processo de expansão das relações capitalistas de produção, sob o rótulo da "modernidade e da civilização". Assim, a disputa sobre os métodos de produção de mapas estava atrelada a uma possível oposição entre a defesa de precisão nos mapeamentos ou de rapidez na consecução dos trabalhos para servir aos interesses pragmáticos da atração de investimentos e os projetos de colonização. De certa maneira, essas disputas refletiam um momento em que noções sobre território, ciência e nação eram utilizadas para defender o processo de integração das áreas consideradas "vazias" e de modernização do País.

La necesidad de producir un mapa general de Brasil para la Exposición Nacional de 1908 generó una gran controversia entre los ingenieros vinculados a la Oficina General de Telégrafos y el club de Ingeniería. En ese período, la producción cartográfica en el territorio brasileño se convirtió en un tema prioritario para los ingenieros y para todos aquellos interesados en promover no solo el conocimiento científico sobre el territorio brasileño, sino también, y especialmente, promover el proceso de expansión de las relaciones de producción capitalistas, bajo la etiqueta de "modernidad y civilización". Por lo tanto, la disputa sobre los métodos de creación de mapas estaba vinculada a una posible oposición entre el mapeo de precisión o la rapidez en la búsqueda de obras para servir a los intereses pragmáticos de los proyectos de atracción de inversiones y colonización. En cierto modo, estas disputas reflejaron un momento en que las nociones sobre territorio, ciencia y nación se utilizaron para defender el proceso de integración de las áreas consideradas "vacías" y la modernización del país.

The need to produce a general map of Brazil for the National Exhibition of 1908 generated a great controversy among engineers linked to the General Telegraph office and the Engineering Club. In that period, cartographic production on the Brazilian territory became a priority subject for engineers and all those interested in advancing not only the scientific knowledge about the Brazilian territory, but also, and especially, to promote the process of expansion of capitalist production relations, under the label of "modernity and civilization". Thus, the dispute over map-making methods was tied to a possible opposition between precision mapping or agility in the pursuit of works to serve the pragmatic interests of investment attraction and colonization projects. In a way, these disputes reflected a moment when notions about territory, science and nation were used to defend the integration process of the areas considered "empty" and modernization of the Country.

La nécessité de produire une carte générale du Brésil pour l'Exposition nationale de 1908 a suscité une vive controverse parmi les ingénieurs liés au bureau du général télégraphe et au club d'ingénierie. À cette époque, la production cartographique sur le territoire brésilien était 
devenue un sujet prioritaire pour les ingénieurs et tous ceux qui souhaitaient faire progresser les connaissances scientifiques sur le territoire brésilien, mais aussi et surtout promouvoir le processus d'expansion des relations de production capitalistes, sous le label "modernité et civilisation". Ainsi, le différend sur les méthodes de cartographie était lié à une possible opposition entre la cartographie de précision et la rapidité dans la poursuite des travaux pour servir les intérêts pragmatiques des projets d'attraction des investissements et de colonisation. D'une certaine manière, ces différends reflétaient un moment où les notions de territoire, de science et de nation ont été utilisées pour défendre le processus d'intégration des zones considérées comme "vides" et la modernisation du pays.

\section{ÍNDICE}

Índice geográfico: Brasil

Palavras-chave: mapa geral do Brasil, Exposição Nacional de 1908, modernização do território, Clube de Engenharia

Mots-clés: carte générale du Brésil, Exposition Nationale de 1908, modernisation du territoire, Club d'Ingénierie

Palabras claves: mapa general de Brasil, Exposición Nacional de 1908, modernización del territorio, Club de Ingeniería

Índice cronológico: 1908

Keywords: general map of Brazil, National Exhibition of 1908, modernization of the territory, Engineering Club

\section{AUTOR}

\section{RILDO BORGES DUARTE}

Instituto Federal do Sul de Minas Gerais - Campus Passos

Doutor em Geografia Humana

rildo.duarte@ifsuldeminas.edu.br 